\title{
EARLY OPEN REDUCTION AND BONE GRAFTING FOR UNSTABLE FRACTURES OF THE DISTAL RADIUS
}

\author{
J. McBIRNIE, C. M. COURT-BROWN, M. M. McQUEEN \\ From the Royal Infirmary of Edinburgh, Scotland
}

We describe a new technique for open reduction, bone grafting and fixation with a single Kirschner wire of unstable fractures of the distal radius. Of the 83 patients treated by this technique, most had regained volar tilt when seen at an average of 13 months after injury. Malunion was seen in 18 patients due either to poor placement of the graft and Kirschner wire or because of both volar and dorsal comminution. Assessment of hand and wrist function showed an average recovery of $63 \%$ of mass grip strength with an excellent return of specialised grip strength and range of movement.

The advantages of this technique over closed methods include the ability to regain the volar tilt of the distal radius and to achieve reduction at any time before union of the fracture.

J Bone Joint Surg [Br] 1995;77-B:571-5.

Received 4 July 1994; Accepted after revision 26 October 1994

There is still controversy surrounding the management of fractures of the distal radius, especially unstable fractures, despite the large numbers treated. Many different methods have been described including pins and plaster (Green 1975), closed Kirschner (K)-wire fixation (Clancey 1984), closed external fixation (Cooney, Linscheid and Dobyns 1979; Weber and Szabo 1986; Jakim, Pieterse and Sweet 1991; Rommens, Vandershot and Broos 1992) and a combination of external fixation and open bone grafting (Leung et al 1989). Remanipulation is commonly used but many studies have shown disappointing results (Lidstrom 1959; Collert and Isaacson 1978; McQueen, MacLaren and Chalmers 1986; Schmalholz 1989).

There is a direct relationship between residual deformity of the wrist and function (Stewart, Innes and Burke 1985;

J. McBirnie, FRCS, Orthopaedic Registrar

C. M. Court-Brown, MD, FRCS Ed(Orth), Consultant Orthopaedic Surgeon

M. M. McQueen, FRCS Ed(Orth), Senior Lecturer and Consultant Orthopaedic Surgeon

Orthopaedic Trauma Unit, The Royal Infirmary of Edinburgh NHS Trust, Lauriston Place, Edinburgh EH3 9YW, UK.

Correspondence should be sent to Miss M. M. McQueen.

C1995 British Editorial Society of Bone and Joint Surgery $0301-620 X / 95 / 41000 \$ 2.00$
Jenkins and Mintowt-Czyz 1988; McQueen and Caspers 1988; Solgaard 1988). If a patient is mentally and physically fit it is important to strive for a good anatomical result.

We describe a prospective study of a new technique for the treatment of unstable fractures of the distal radius by early open reduction and bone grafting.

\section{PATIENTS AND METHODS}

Between August 1988 and January 1993, a total of 83 patients underwent open reduction and bone grafting. Before operation all had had successful closed manipulation of their fractures under regional anaesthesia with immobilisation in a below-elbow plaster-of-Paris backslab. Instability was defined as loss of position in the cast to more than $12^{\circ}$ of dorsal angulation and more than $4 \mathrm{~mm}$ of radial shortening after reduction.

There were 73 women and $10 \mathrm{men}$; their average age was 60 years (16 to 82 ). The injury had been due to a simple fall in $86 \%$. In the remainder it had resulted from a sports injury $(7 \%)$, a fall from a height $(5 \%)$ or a roadtraffic accident (2\%). Each fracture was classified using the Frykman (Frykman 1967) and the AO classifications (Müller et al 1990). The type of comminution was also assessed.

Thirty per cent of fractures were AO type A3.2 (extraarticular, metaphyseal multifragmentary); $70 \%$ were $\mathrm{AO}$ type $\mathrm{C}$ of which two-thirds were C2.1 (simple articular, sagittal articular fracture line, metaphyseal multifragmentary) and one-third AO type C3.2 (complex articular, metaphyseal multifragmentary) except for one patient with a type C3.3 fracture (comminution extending into the diaphysis). Most fractures were Frykman type VII or type VIII (Table I).
Table I. Fracture type of 83 patients according to Frykman classification

\begin{tabular}{ccc}
\hline Classification & $\begin{array}{l}\text { Number } \\
\text { of patients }\end{array}$ & Percentage \\
\hline I to II & 8 & 10 \\
III to IV & 4 & 5 \\
V to VI & 17 & 20 \\
VII to VIII & 54 & 65 \\
\hline
\end{tabular}




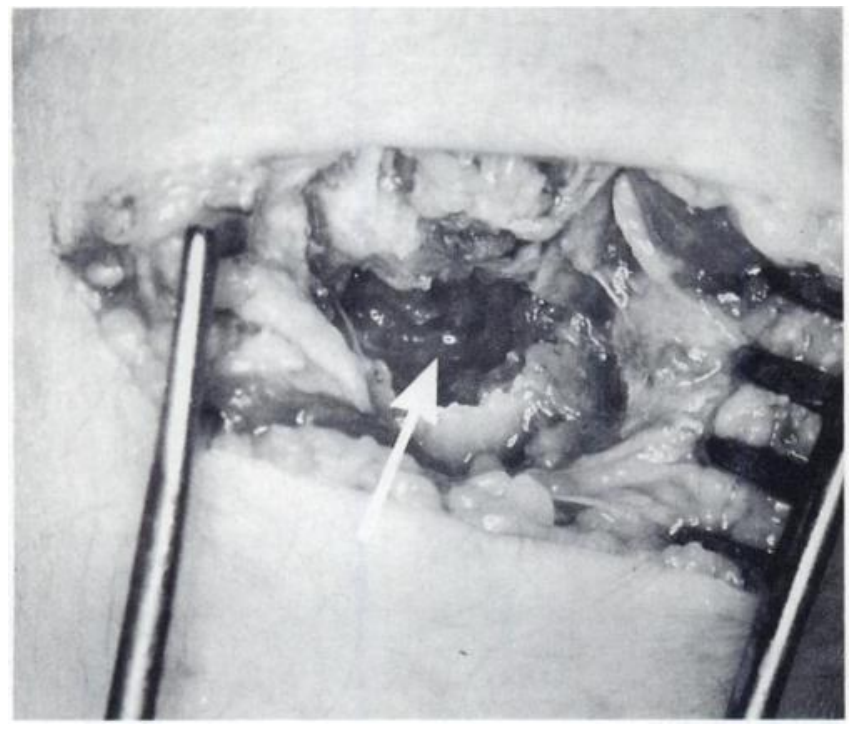

Fig. 1

Open reduction of the fracture showing the dorsal defect (arrow).

There was comminution of the dorsal cortex in 74 patients, in eight of both volar and dorsal cortices and in one there was no identifiable cortical comminution.

Operation was performed at an average of 14 days after the injury (1 to 28 ).

Radiological and functional reviews were at an average of 13 months ( 4 to 29) after operation. Measurements of the dorsal angle, radial shift (Van der Linden and Ericson 1981) and radial shortening (Melone 1986) were made on the initial radiographs, immediately before surgery, postoperatively and at the final review. Displacement at the time of injury averaged $25^{\circ}$ of dorsal angulation (6 to 55$), 3 \mathrm{~mm}$ of radial shift $(-3$ to +10$)$ and $3 \mathrm{~mm}$ of radial shortening ( -2 to +10$)$. Immediately before operation the dorsal angulation was an average of $19^{\circ}$ (15 to 35), the radial shift $3 \mathrm{~mm}$ ( -3 to +10$)$ and the radial shortening $3 \mathrm{~mm}(-2$ to +10$)$.

Wrist and hand function was tested by a research occupational therapist who had no knowledge of the radiological result. Grip strength was assessed using the Jamar dynamometer (Bechtol 1954) and specialised grip strength by the Musur-Grieve spring balance (Musur-Grieve 1984) with interchangeable handles to allow assessment of hook, cylinder, key, chuck and pinch grips. The ability to perform both unilateral and bilateral activities of daily living was scored (Sheehan, Sheldon and Marks 1983). The range of movement was measured in both wrists using a goniometer and expressed as a percentage of the normal opposite wrist. Pain was assessed using an analogue scale from 0 to 10 . The cosmetic appearance of the wrist was reviewed by the examiner.

Malunion was defined as more than $12^{\circ}$ of dorsal angulation or more than $4 \mathrm{~mm}$ of radial shortening.

Operative technique. Under tourniquet control a transverse incision is made on the dorsum of the wrist down to

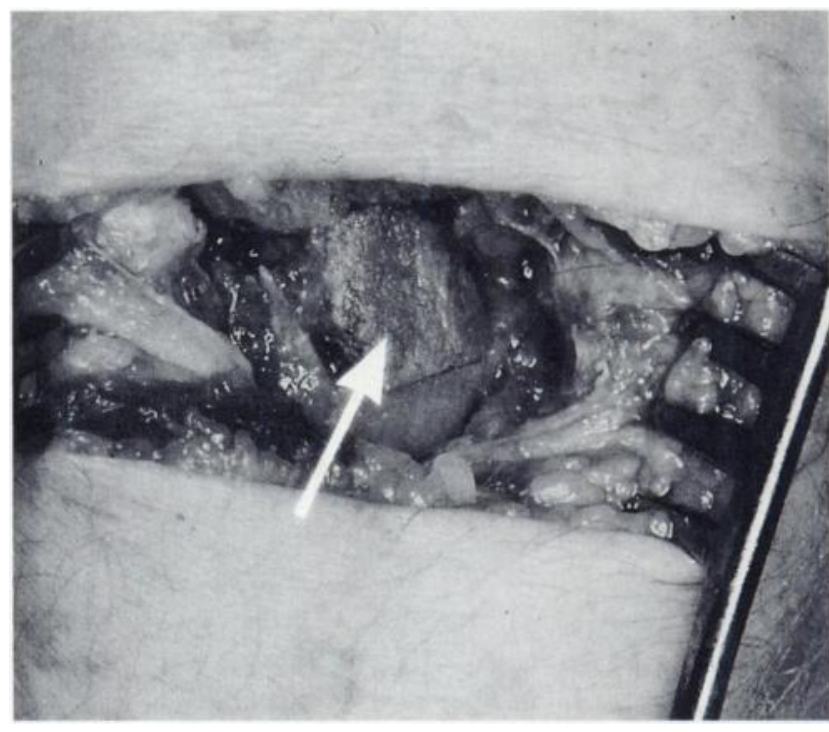

Fig. 2

The dorsal defect filled with bone graft.

the extensor retinaculum at the level of the fracture. Care is taken to protect the terminal branch of the radial nerve. A longitudinal incision is made in the extensor retinaculum protecting the tendon of extensor pollicis longus which traverses the incision. The fracture site is identified and elevated. This leaves a defect in the dorsal cortex (Fig. 1) which is filled by a triangular wedge of corticocancellous bone taken from the iliac crest (Fig. 2).

The bone graft is seated well into the defect and care is taken to ensure that the cortex of the graft is flush with the dorsal cortex of the radius. A K-wire is then inserted from the radial styloid diagonally across the distal radius engaging the graft and the more proximal cortex of the radius (see Fig. 3b). Radiographs are taken to ensure satisfactory siting of both the graft and the wire. The end of the K-wire is then cut just deep to the skin, the wound is closed and the wrist placed in a forearm plaster which is retained for six weeks. The $\mathrm{K}$-wire is taken out at the time of removal of the plaster. Figure 3 shows a series of radiographs of a patient treated in this way.

\section{RESULTS}

Complications. Complications occurred in 39 patients (47\%), minor in $13(16 \%)$ and major in $26(31 \%)$ (Table II) with 18 fractures proceeding to malunion. If malunion is excluded 21 patients $(25 \%)$ had complications with eight (10\%) having major problems.

Radiological results. At final review the average dorsal angulation was $-2^{\circ}(-25$ to +23$)$. The average radial shift was $4 \mathrm{~mm}(-3$ to +9$)$ and the average radial shortening $0 \mathrm{~mm}(-4$ to +7$)$. Malunion was seen in 18 patients with either excessive dorsal angulation, excessive volar angulation or a combination of either of these with shortening. 

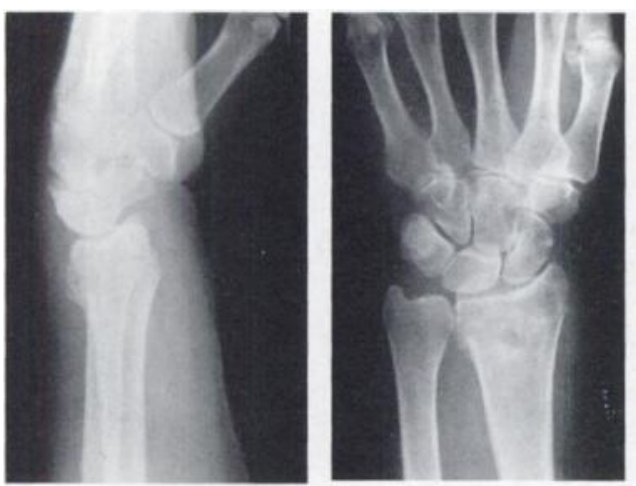

Fig. 3a
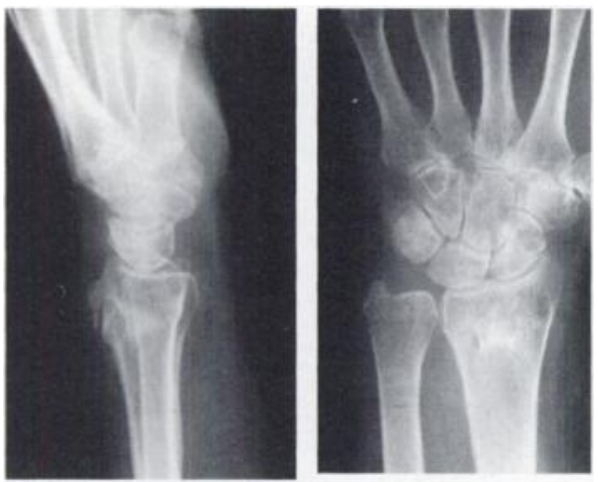

Fig. 3c

Table II. Complications in 39 patients

\begin{tabular}{lc}
\hline & $\begin{array}{l}\text { Number } \\
\text { of patients }\end{array}$ \\
\hline Major & 18 \\
$\quad$ Malunion & 4 \\
Carpal tunnel syndrome & 1 \\
Reflex sympathetic dystrophy & 1 \\
Extensor pollicis longus rupture & 1 \\
Extensor pollicis longus division & 1 \\
Frozen shoulder & 26 \\
Total & \\
Minor & 8 \\
K-wire site infection & 2 \\
Dorsal radial-nerve neurapraxia & 3 \\
Superficial wound infection & 13 \\
Total & \\
\hline
\end{tabular}

Eight patients had dorsal angulation with or without shortening caused by poor positioning of either the bone graft or $\mathrm{K}$-wire, allowing late collapse. Ten patients had volar angulation with or without shortening, two because of poor positioning of the bone graft and $\mathrm{K}$-wire. In seven of these there was identifiable volar and dorsal comminution on the original radiographs, but in one there was no obvious reason for the collapse into volar angulation.
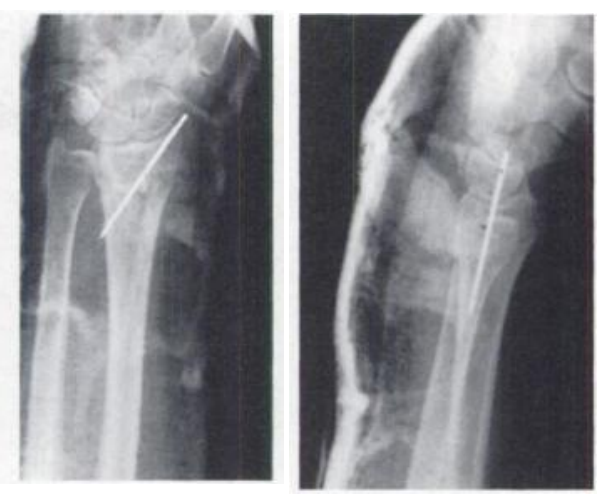

Fig. 3b

Figure 3a - Radiographs of a distal radial fracture one week after satisfactory reduction showing collapse into dorsal angulation and shortening. Figure $3 b$ - After open reduction and bone grafting. The $K$ wire is correctly placed. Figure $3 c-$ Final result one year later.

Functional results. Mass grip strength had recovered to an average of $63 \%$ of the normal opposite side (6.5 to 100$)$. Specialised grip strength had recovered to over $90 \%$ of the normal side for all types measured.

Recovery of the unilateral activities of daily living was to an average of $94 \%$ of full activity (40 to 100). For bilateral activities recovery was full in most patients $(78 \%$ to $100 \%$ ).

Recovery of wrist movement was generally good with most patients achieving over $80 \%$ of the normal range (Fig. 4). At final review flexion averaged $73 \%$ of normal (26 to 100 ) and extension $75.5 \%$ (10 to 100). Pronation recovered to $93 \%$ (34 to 100) and supination to $85 \%$ of normal (23 to 100 ). Radial and ulnar deviation recovered to $83 \%$ (26 to 100 ) and $74 \%$ of normal (10 to 100 ), respectively.

Pain was absent in $58 \%$ of patients. Of the remainder, $20 \%$ had mild pain (0 to 3 on an analogue score), 19\% moderate (4 to 7 on an analogue score), and 3\% severe pain (8 to 10 on an analogue score).

Cosmetic deformity was considered to be absent in $54 \%$ of patients; $32 \%$ had a mild deformity and $14 \%$ moderate deformity.

\section{DISCUSSION}

The use of early open reduction and bone grafting for unstable fractures of the distal radius without major intra- 


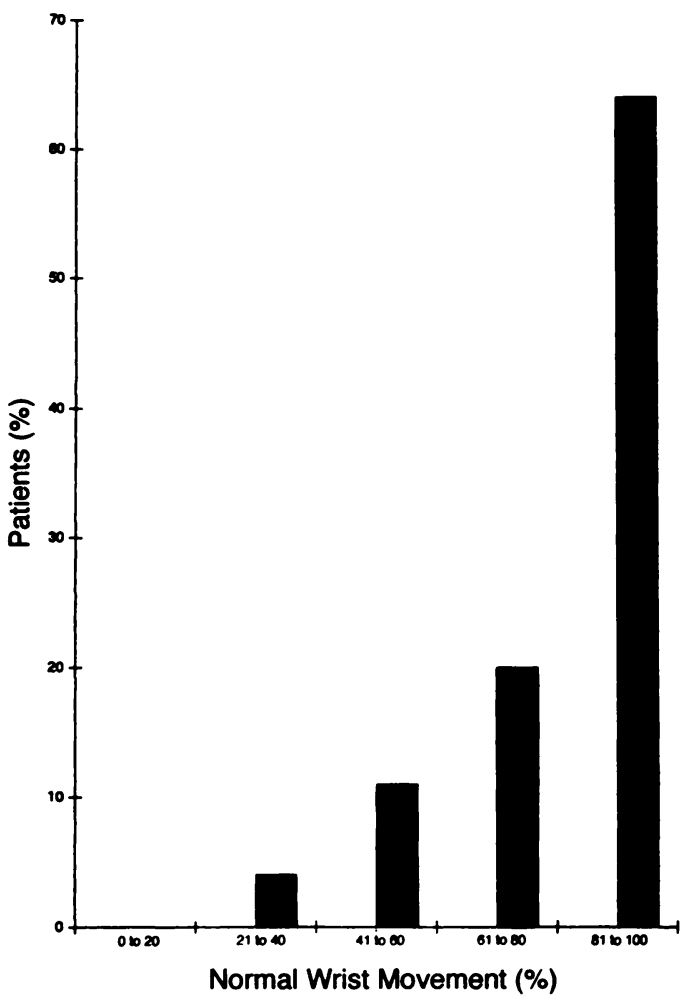

Fig. 4

Mean range of movement in 83 patients at one year.

articular displacement has not previously been described. Our study has shown that this technique produces excellent anatomical results in most patients. Leung et al (1989) have described a method of treating such fractures by bone grafting but they used an external fixator in combination with cancellous bone.

The use of a block of corticocancellous bone rather than small fragments of cancellous bone gives sufficient stability without the need for external fixation. Bone grafting is required for mechanical support rather than to stimulate healing and it is logical to use a bone block rather than small pieces of cancellous bone. Previous reports of the use of bone grafting in unstable fractures of the distal radius have concentrated on severely displaced articular injuries in which open treatment and bone grafting are necessary to restore articular congruity (Melone 1986; Fernandez and Geissler 1991). Open reduction and internal fixation without bone grafting have also been used for volar displaced fractures of the distal radius (Keating, Court-Brown and McQueen 1994).

Early open reduction and bone grafting have the advantage over closed techniques of restoring the volar tilt. Ligamentotaxis has been shown to be an unreliable method of achieving this both experimentally (Bartosh and Saldana 1990) and in clinical practice (Cooney et al 1979; McQueen, Michie and Court-Brown 1992). Restoration of palmar tilt may be significant in restoring normal function since loss of the normal palmar tilt may cause the carpus to collapse dorsally (Taleisnik and Watson 1984).

Using this open technique, rereduction can be achieved at any time before fracture union, but further closed manipulation is only possible in the early days after injury.

Although most of our patients had good anatomical results a significant proportion remained with malunion in either dorsal angulation or excessive volar angulation, with or without shortening. The dorsal malunions were all related to poor seating of the bone graft or poor placement of the K-wire and most occurred early in the series. We now recommend that the position of the graft and $\mathrm{K}$-wire is checked radiographically during the operation.

Excessive volar angulation occurs in fractures with a combination of volar and dorsal comminution in which the bone graft, inserted dorsally, prevents dorsal collapse, but the absence of a volar buttress allows gradual progression into volar angulation. This operation is not recommended where there is both volar and dorsal comminution except by experienced surgeons. The exclusion of these patients and care in positioning of the graft and the $\mathrm{K}$-wire should achieve a low rate of malunion.

Recovery of mass grip strength to an average of $63 \%$ of normal is disappointingly low but is comparable with a previous series of unstable fractures of the distal radius treated by external fixation (McQueen et al 1992). Difficulties with the activities of daily living were usually with those requiring grip strength. Reduction in strength may be an indication of the severity of the associated soft-tissue injury.

The complication rate of $47 \%$ is comparable with that of other series of similar fractures treated by external fixation (McQueen et al 1992). Other reported complication rates for external fixation range from $27 \%$ (Cooney et al 1979) to 62\% (Weber and Szabo 1986). Cooney, Dobyns and Linscheid (1980) described a major complication rate of $31 \%$ in a large series of distal radial fractures treated by a variety of methods.

The need for a donor site is a disadvantage of this technique although we had no significant complications related to this. It may be possible to use biosynthetic material in the future.

Conclusions. Open reduction and bone grafting is a useful method for the management of these redisplaced fractures. Volar tilt of the distal radius can be restored at any time before union and maintained provided the technique is used correctly. The functional results and rates of complication are comparable with those of other techniques.

The authors wish to acknowledge the support of the Wishbone Trust in carrying out this study.

Although none of the authors have received or will receive benefits for personal or professional use from a commercial party related directly or indirectly to the subject of this article, benefits have been or will be received but are directed solely to a research fund, foundation, educational institution, or other non-profit institution with which one or more of the authors is associated. 


\section{REFERENCES}

Bartosh RA, Saldana MJ. Intra-articular fractures of the distal radius: a cadaveric study to determine if ligamentotaxis restores radiopalmar tilt. J Hand Surg 1990;15:18-21.

Bechtol CO. Grip test: the use of a dynamometer with adjustable handle spacings. J Bone Joint Surg [Am] 1954;36-A:820-4.

Clancey GJ. Percutaneous Kirschner-wire fixation of Colles' fractures: a prospective study of thirty cases. J Bone Joint Surg [Am] 1984;66-A: 1008-14.

Collert S, Isaacson J. Management of redislocated Colles' fractures. Clin Orthop 1978;135:183-6.

Cooney WP III, Dobyns JH, Linscheid RL. Complications of Colles' fractures. J Bone Joint Surg [Am] 1980;62-A:613-9.

Cooney WP III, Linscheid RL, Dobyns JH. External pin fixation for unstable Colles' fractures. J Bone Joint Surg [Am] 1979;61-A:840-5.

Fernandez DL, Geissler WB. Treatment of displaced articular fractures of the radius. J Hand Surg 1991;16:375-84.

Frykman G. Fracture of the distal radius including sequelae-shoulderhand-finger syndrome, disturbance in the distal radio-ulnar joint and impairment of nerve function: a clinical and experimental study. Acta Orthop Scand 1967;Suppl 108.

Green DP. Pins and plaster treatment of comminuted fractures of the distal end of the radius. J Bone Joint Surg [Am] 1975;57-A:304-10.

Jakim I, Pieterse HS, Sweet MBE. External fixation for intra-articular fractures of the distal radius. J Bone Joint Surg [Br] 1991;73-B:3026.

Jenkins NH, Mintowt-Czyz WJ. Mal-union and dysfunction in Colles' fracture. J Hand Surg [Br] 1988;13-B:291-3.

Keating JF, Court-Brown CM, McQueen MM. Internal fixation of volar-displaced distal radial fractures. J Bone Joint Surg [Br] 1994; 76-B:401-5.

Leung KS, Shen WY, Leung PC, et al. Ligamentotaxis and bone grafting for comminuted fractures of the distal radius. J Bone Joint Surg [Br] 1989;71-B:838-842.

Lidstrom A. Fractures of the distal end of the radius: a clinical and statistical study of end results. Acta Orthop Scand 1959;Suppl 141.

McQueen MM, MacLaren A, Chalmers J. The value of remanipulating Colles' fractures. J Bone Joint Surg [Br] 1986;68-B:232-3.
McQueen M, Caspers J. Colles' fracture: does the anatomical result affect the final function? J Bone Joint Surg [Br] 1988;70-B:649-51.

MeQueen MM, Michie M, Court-Brown CM. Hand and wrist function after external fixation of unstable distal radial fractures. Clin Orthop 1992;285:200-4.

Melone CP Jr. Open treatment for displaced articular fractures of the distal radius. Clin Orthop 1986;202:103-11.

Müller ME, Nazarian S, Koch P, Schatzker J. The comprehensive classification of fractures of long bones. Berlin, etc: Springer-Verlag, 1990.

Musur-Grieve M. Methods of assessment and management of the rheumatoid hand at the Institue of Rheumatology, Warsaw, Poland. In: Hunter JM, Schneider LH, Mackin EJ, Callahan AD, eds. Rehabilitation of the hand. Second ed. St Louis, etc: C. V. Mosby, 1984: 651-62.

Rommens PM, Vandershot PM, Broos PL. External fixation of the distal end of the radius: the same technique for different patient populations? Arch Orthop Trauma Surg 1992;111:165-70.

Schmalholz A. Closed reduction of axial compression in Colles' fractures is hardly possible. Acta Orthop Scand 1989;60:57-9.

Sheehan NJ, Sheldon JF, Marks D. Grip strength and torquometry in the assessment of hand function in patients with rheumatoid arthritis. $\mathrm{Br} \mathrm{J}$ Rheumatol 1983;22:158-64.

Solgaard S. Function after distal radius fracture. Acta Orthop Scand 1988;59:39-42.

Stewart HD, Innes AR, Burke FD. Factors affecting the outcome of Colles' fracture: an anatomical and functional study. Injury 1985; 16:289-95.

Taleisnik J, Watson HK. Midcarpal instability caused by malunited fractures of the distal radius. J Hand Surg 1984;9:350-7.

Van der Linden W, Ericson R. Colles' fracture: how should its displacement be measured and how should it be immobilized? $J$ Bone Joint Surg [Am] 1981;63-A:1285-8.

Weber SC, Szabo RM. Severely comminuted distal radial fracture as an unsolved problem: complications associated with external fixation and pins and plaster techniques. J Hand Surg [Am] 1986;11-A:157-65. 